\title{
Post-harvest respiration of Pinus radiata logs under different temperature and storage conditions
}

\author{
Jinquan Feng ${ }^{1 *}$, Allan Woolf ${ }^{1}$, Xingyun Yang ${ }^{1}$, Shane Olsson ${ }^{1}$, Don Brash², Alistair Hall ${ }^{2}$ and Bruce Bycroft ${ }^{2}$
}

\begin{abstract}
Background: Radiata pine (Pinus radiata D.Don) log exports are a growing and important trade for New Zealand. Oxygen $\left(\mathrm{O}_{2}\right)$ depletion and carbon dioxide $\left(\mathrm{CO}_{2}\right)$ accumulation in ship holds caused by log respiration may affect the efficacy of fumigation treatments and safety to people working around the holds. Currently very little is known about changes in respiration rates of harvested logs. This study examined the respiration rate of harvested logs after temperature equalisation overnight to a range of temperatures and when stored at typical indoor or outdoor conditions to identify key factors affecting log respiration rate.

Results: The results indicate that the respiration rate of logs increased as a function of temperature following Arrhenius' equation, with activation energy (Ea) value of $27708 \mathrm{~J} \mathrm{~mol}^{-1}$. The respiration rate at a reference temperature of $20^{\circ} \mathrm{C}$ decreased from $25.1 \mathrm{mg} \mathrm{CO}_{2} \mathrm{~kg} \mathrm{DW}^{-1} \mathrm{~h}^{-1}$ one week after harvest to 16.2 and $11.5 \mathrm{mg}$ $\mathrm{CO}_{2} \mathrm{~kg} \mathrm{DW}^{-1} \mathrm{~h}^{-1}$ three and six weeks after harvest, respectively. The dominant respiration tissue shifted from cambial and parenchymatous tissues in 'fresh' logs towards the internal sapwood over a six-week period. This shift may be attributed to severe dehydration of the outer layers. Microbial activity also contributed to the respiration of logs when stored at humid conditions.

Conclusion: Irrespective of storage conditions, the rates of respiratory $\mathrm{CO}_{2}$ release of log sections remained high during the first two weeks post harvest and declined rapidly within the next a few weeks as logs become dehydrated. Respiration rates at a given storage time increased nearly $50 \%$ for every $10{ }^{\circ} \mathrm{C}$ increase in temperature from 10 to $40^{\circ} \mathrm{C}$. Drying logs for $4-6$ weeks before fumigation treatment at moderate temperature may help to achieve consistent fumigation results, prevent life-threatening conditions and to reduce transportation cost.
\end{abstract}

Keywords: Temperature; Moisture; Storage condition; Wood tissue; Microbial growth

\section{Background}

Radiata pine (Pinus radiata D.Don) log exports are a growing and important trade for New Zealand. New Zealand exported 16 million $\mathrm{m}^{3}$ of logs in the year to June 2013, worth \$NZ2.3 billion (MPI 2013). Logs are usually exported within six weeks of harvest and are transported by ships. Approximately $70 \%$ of the log cargo is stowed in closed holds and the remainder are top-stowed on the open deck. Typical in-transit transport time from when loading commences to markets is $20-25$ days. Fumigation to control insect pests is usually carried out either in-

\footnotetext{
* Correspondence: ringo.feng@plantandfood.co.nz

${ }^{1}$ The New Zealand Institute for Plant \& Food Research Limited, 120 Mt Albert Rd, Auckland 1142, New Zealand

Full list of author information is available at the end of the article
}

transit for within-hold stowed logs or on dockside for top deck-stowed logs. Fumigation of radiata pine logs in the past heavily depended on the use of the insecticide methyl bromide but the use of methyl bromide is due to stop in the future because of its ozone depleting effect. Therefore, research has been set up to replace methyl bromide with more environmentally acceptable pesticides, such as phosphine and other alternatives. However, the efficacy of these alternative treatments has been found to be impaired by high $\mathrm{CO}_{2}$ and low $\mathrm{O}_{2}$ concentrations in log holds caused by log respiration (Brash and Page, 2009).

Svedberg et al. (2009) found that oxygen $\left(\mathrm{O}_{2}\right)$ concentration inside ship holds loaded with logs and wood chips declined to a mean of $10 \pm 7.3 \%$ over a mean period of $46 \mathrm{~h}$

\section{实}


after loading. Concomitantly, $\mathrm{CO}_{2}$ concentration increased to a mean of $7.5 \pm 5.2 \%$. This indicates that the atmosphere inside holds may become life-threatening within two to three days after loading. The changes in atmosphere were thought to be a consequence of wood respiration, biomass decomposition and microbiological activities (Svedberg et al. 2009; Fan \& Bi 2013). Literature on the post-harvest respiration rate of logs is rare. Most studies focus on the respiration rate of living stems (Ryan et al. 1994; Damesin et al. 2002; Guidolotti et al. 2013; Rodriguez-Calcerrada et al. 2014) or coarse wood litter (Progar et al. 2000; Chambers et al. 2001). For both living stems and coarse wood litter, respiration rate increases as temperatures rise within a day or throughout the year, although discrepancies exist because of genetic, developmental and other environmental factors, such as shelter, which affects moisture content, and heterotrophic community composition (Progar et al. 2000; Rodriguez-Calcerrada et al. 2014). Therefore, it is expected that the respiration rates of harvested radiata pine logs also respond to temperature, storage condition and time.

We evaluated the respiration rate of harvested radiata pine logs at a range of temperature and storage conditions. The aims were to identify factors affecting log respiration and to use this information to predict the potential modification of the atmosphere in a sealed headspace.

\section{Methods}

Three typical logs, $4.8 \mathrm{~m}$ long and $0.2-0.3 \mathrm{~m}$ in diameter were commercially harvested on 17 January 2013 from a forest approximately 25-28 years old in Wanganui, New Zealand. The logs were commercially de-limbed as an industry practice, which retained about $20 \%$ bark by surface area. A total of 48 sections, each $0.29 \mathrm{~m}$ long, were cut from three replicate logs. Each section was paraffin wax-sealed at both ends as described by Pranamornkith et al. (2014). These log sections were then designated into four sets of twelve log sections for experiments started one week after harvest. Each set consists of four log sections from each replicate logs.

\section{Effect of temperature on respiration rate}

This first experiment aimed to determine the effect of temperature on respiration rate using three sets of twelve $\log$ sections. Each of these was assessed one, three and six weeks after harvest, respectively. The log sections were stored at ambient temperature in a ventilated room before respiration measurements commenced. At each assessment time, twelve log sections were equilibrated to four different temperatures of $10,20,30$ and $40{ }^{\circ} \mathrm{C}$ (three log sections for each temperature) overnight before measuring the respiration rate (record of temperature at the centre of log sections indicated that temperature equilibration overnight is sufficient to get internal temperature to within in $1{ }^{\circ} \mathrm{C}$ from the targeted temperature). The four temperatures cover the temperature range that logs may possibly experience in transit.

Each $\log$ section was then sealed in a 20-L food grade plastic bucket. Headspace $\mathrm{CO}_{2}$ concentration was measured at different intervals until a concentration of $0.5-1.0 \% \mathrm{CO}_{2}$ was reached; this concentration range was selected to ensure the measured value was sufficiently higher than detection limit of the analyser $\left(0.01 \% \mathrm{CO}_{2}\right)$. The $\mathrm{CO}_{2}$ concentration of the headspace was measured using $1 \mathrm{~mL}$ of gas sampled from each sealed container using the method described by Hertog et al. (2003). Briefly, gas samples were analysed using a miniature infrared $\mathrm{CO}_{2}$ analyser (Analytical Development Company, Hoddesdon, UK). Output signals were linear over the range applied and analysed using HP integrators (Hewlett-Packard, model 3396A). The time to reach $0.5-1.0 \% \mathrm{CO}_{2}$ in the headspace typically took around $40-100 \mathrm{~min}$, depending on temperature and storage time.

The weight of each log section was measured at the beginning of the experiment (initial weight one week after harvest) and again after respiration measurements, allowing the calculation of moisture content. The dry weight of each log section was calculated based on the initial weight and an initial moisture content of $54 \%$ as measured on additional logs of the same harvest (Dry weight $=$ Initial weight $\mathrm{x}(1-0.54))$. Respiration rate was calculated on a dry weight basis.

\section{Spatial variation in respiration rate}

The second experiment investigated the spatial variation in respiration rate from the bark/cambium layer towards the centre of the log. The purpose of this was to show which part of the log was most actively respiring at a given interval postharvest.

Three log sections used for respiration measurement at $20{ }^{\circ} \mathrm{C}$ in the temperature experiment described above were used here also. Each log section was cut into eight blocks approximately $90 \mathrm{~mm}$ in length, $90 \mathrm{~mm}$ in width and $10 \mathrm{~mm}$ in thickness across the log section (Fig. 1). Blocks one and eight represent the outermost zone containing bark and cambium; blocks two and seven represent the outer part of the log; blocks three and six represent sapwood; and blocks four and five represent the heartwood of the log section. These blocks were weighed and then sealed in 1-L respiration jars at $20{ }^{\circ} \mathrm{C}$ for up to four hours before headspace gas measurements were taken to determine respiration rate. The moisture content of each block was measured by weighing before and after a 72-h drying period at $105^{\circ} \mathrm{C}$. 


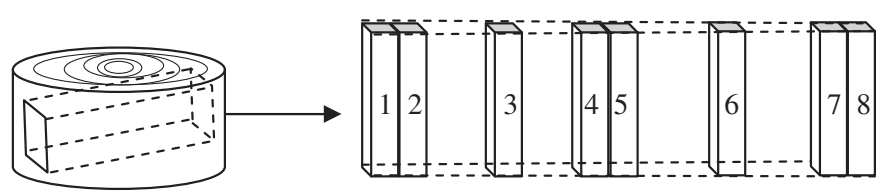

Log section Bark/cambium Sapwood Heartwood Sapwood Cambium/bark

Fig. 1 Eight blocks of wood tissue cut from each radiata pine log section for the measurement of spatial variation in respiration rate

\section{Effect of storage condition on respiration rate}

The third experiment evaluated the effect of storage conditions on respiration rate over time. Twelve log sections were stored in four different environmental conditions with three replicate sections in each:

A. Indoor dry air; three log sections stored in a 360-L plastic container flushed with dry air with approximately $50 \%$ relative humidity

B. Indoor humid air; three log sections stored in a 360-L plastic container flushed with humidified air with approximately $98 \%$ relative humidity

C. Outdoor covered; three log sections stored in a plastic crate located outside with cover using a plastic film and a cardboard sheet to prevent direct exposure to rain and sunshine

D. Outdoor uncovered; three log sections stored in a plastic crate located outside without cover.

The respiration rate was measured on each log section at seven times during storage: one, two, three, five, six, twelve and twenty four weeks after harvest to reflect time when logs are transported. Log sections were equilibrated at $20{ }^{\circ} \mathrm{C}$ overnight before being sealed in $20-\mathrm{L}$ plastic buckets for respiration measurement at $20^{\circ} \mathrm{C}$.

The weight of each log section was recorded on each measurement date to allow calculation of respiration rate and weight loss over time. The volumes of the three log sections stored in humidified air were measured after the final respiration measurement by submerging each $\log$ section into a 20-L plastic bucket full of water. The volume of water that overflowed from the bucket was taken as the volume of the log section. Log density at the beginning of the experiment was calculated as the ratio between initial weight and log volume (volume change should be negligible for log sections stored in humidified air). The average density of these three $\log$ sections $\left(0.90 \mathrm{~kg} \mathrm{~L}^{-1}\right)$ was used to calculate initial volume of all log sections based on initial weight.

The experimental data were analysed using a nonlinear regression procedure for temperature effects and a general linear model procedure for tissue zone difference or the effects of storage treatments. All the analyses were carried out using Statistical Analysis System, version 9.4 (SAS Inc., USA).

\section{Results and discussion}

\section{Effect of temperature on respiration rate}

Respiration rates $\left(r \mathrm{CO}_{2}\right)$ measured at week one increased 3.2-fold with a temperature increase from 10 to $40{ }^{\circ} \mathrm{C}$ (16.3 vs. $51.4 \mathrm{mg} \mathrm{CO}_{2} \mathrm{~kg} \mathrm{DW} \mathrm{h}^{-1}$ ). Respiration rates measured at week three and week six showed a similar response to temperature, and a clear decline in overall respiration rate was obvious, with up to $50 \%$ lower $r \mathrm{CO}_{2}$ towards the end of the measurement period (Fig. 2). The respiration rates increased 3.2-fold with a temperature increase from 10 to $40{ }^{\circ} \mathrm{C}$ (16.3 vs. $51.4 \mathrm{mg}$ $\mathrm{CO} 2 \mathrm{~kg} \mathrm{DW} \mathrm{h}^{-1}$ ).

The increase in respiration rate was described as a function of temperature following Arrhenius' equation (Equation 1).

$$
r_{\mathrm{CO}_{2}}=r_{\mathrm{CO}_{2} \text { ref }} e^{\left(\left(\frac{E a}{R}\right)\left(\frac{1}{T_{\text {ref }}}-\frac{1}{T}\right)\right)}
$$

where $r \mathrm{CO}_{2 \text { ref }}$ is the $\mathrm{rCO}_{2}$ measured at a reference temperature of $20{ }^{\circ} \mathrm{C}$; $E a$ is the activation energy; $R$ is the universal gas constant $\left(8.314 \mathrm{~J} \mathrm{~mol}^{-1} \mathrm{~K}^{-1}\right) ; T_{\text {ref }}=293 \mathrm{~K}$ $\left(20^{\circ} \mathrm{C}\right)$; and $T$ is temperature $(\mathrm{K})$ of log sections during respiration measurement. A high value of $E a$ indicates high temperature sensitivity.

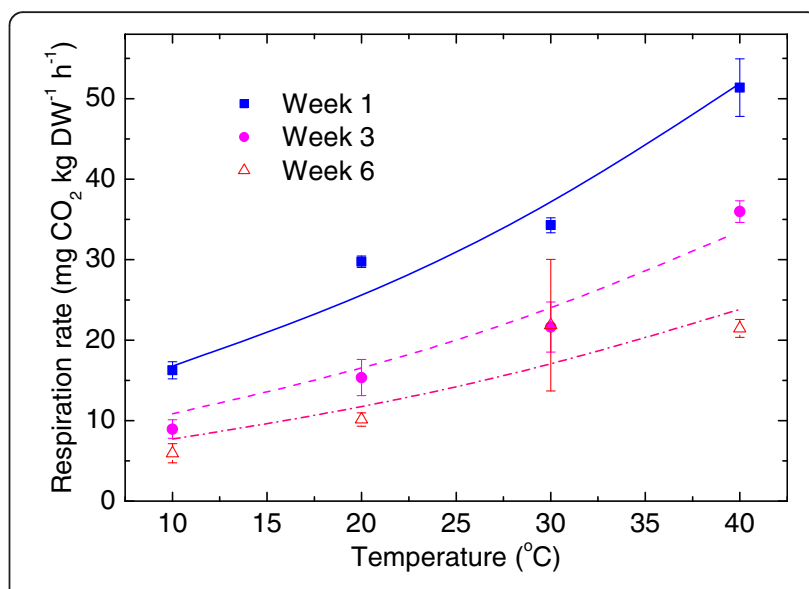

Fig. 2 Effect of temperature on respiration rate of radiata pine logs on a dry weight basis. Each point is the means of three replicate log sections. Vertical bars are standard errors of the means. Lines represent the Arrhenius' model fitted to the data, with parameters listed in Table 1 
A generic model fitted to combined data from three assessments made one, three and six weeks after harvest had a $R^{2}$ value of 0.87 and a root mean squared error (RMSE) of $5 \mathrm{mg} \mathrm{CO} \mathrm{kg} \mathrm{FW}^{-1} \mathrm{~h}^{-1}$. The estimated value for reference respiration rate at $20{ }^{\circ} \mathrm{C}$ decreased from $25.1 \mathrm{mg} \mathrm{CO} \mathrm{kg} \mathrm{DW}^{-1} \mathrm{~h}^{-1}$ one week after harvest to $11.5 \mathrm{mg} \mathrm{CO}_{2} \mathrm{~kg} \mathrm{DW}^{-1} \mathrm{~h}^{-1}$ six weeks after harvest $(46 \%$ decrease). The activation energy estimated was 27708 $\mathrm{J} \mathrm{mol}^{-1}$ (Table 1 and Fig. 2). These results are consistent with the exponential increase in $\mathrm{CO}_{2}$ flux observed for tree trunks as a function of increasing temperature (Rodriguez-Calcerrada et al. 2014). The parameters listed in Table 1 could be used to estimate respiration rates at any temperature between 10 and $40{ }^{\circ} \mathrm{C}$ based on respiration rate measured at a $20^{\circ} \mathrm{C}$. Based on the $E a$ value of $27708 \mathrm{~J} \mathrm{~mol}^{-1}$, respiration rate will increase nearly $50 \%$ for every $10^{\circ} \mathrm{C}$ increase in temperature.

\section{Spatial variation in respiration rate}

At the first assessment made one week after harvest, the respiration rate measured on wood blocks showed a clear pattern indicating a reduction of respiration rate from the bark/cambium layer towards the heartwood. However, this pattern became less pronounced three weeks after harvest, and the wood blocks cut off half way between the bark/cambium layer and the heartwood had the highest rate of respiration rate six weeks after harvest (Fig. 3a). The significant reduction in respiration rate of outer layers over time may have been a consequence of severe water loss in the layers (Fig. 3b). It was also noticed that the two bark samples (Blocks one and eight) from opposite sides of the log have significantly different respiration rates at weeks 1 and 3 (Fig. 3a). This difference could be attributed to the difference in moisture content (Fig. 3b), which could be the consequence of stacking log sections horizontally (the side facing down and touching ground or other logs beneath may have lost less water than the opposite side. The average respiration rates across different zones $(65.6,27.3$ and $11.9 \mathrm{mg} \mathrm{CO} 2 \mathrm{~kg}$ $\mathrm{DW}^{-1} \mathrm{~h}^{-1}$ respectively as measured one, three and six weeks after harvest) were higher than the $r_{\mathrm{CO}_{2}}$ values measured for log sections at the same temperature (Fig. 3), particularly for week one (1.6 times higher)

Table 1 Parameters of equation 1 estimated using combined data from three assessment times $(\mathrm{N}=36)$

\begin{tabular}{llllll}
\hline Parameter & Week & Estimate & se & $\mathrm{R}^{2}$ & RMSE \\
\hline$r_{\mathrm{CO}_{2} \text { ref }}$ & 1 & 25.08 & 1.60 & & \\
$\left(\mathrm{mmol} \mathrm{CO} \mathrm{kg}^{-1} \mathrm{~h}^{-1}\right)$ & 3 & 16.22 & 1.32 & & \\
& 6 & 11.52 & 1.20 & 0.87 & 5.00 \\
$\mathrm{Ea}\left(\mathrm{J} \mathrm{mol}{ }^{-1}\right)$ & All & 27708 & 2780 & & \\
\hline
\end{tabular}

and week three (0.7 times higher). These differences could be attributed to the reduction in resistance to gas diffusion within wood tissue compared with that in log sections $\left(\mathrm{CO}_{2}\right.$ from respiration was more freely released to the respiration jar when the wood was cut into small pieces than from the whole log section because of the increased surface to mass ratio and the decreased distance from inside to outside). Therefore, the respiration rate measured on small blocks of log tissues in the current study serves as an indication of potential respiration activity of different tissue zones. However, prediction of ship-hold atmospheres should be based on the respiration rate measured on log sections rather than that measured on small blocks of log tissue. The respiration rates measured on log sections should be useful for predicting initial changes in shiphold atmospheres before $\mathrm{O}_{2}$ depletion and consequent $\mathrm{CO}_{2}$ accumulation becomes a limiting factor for full expression of respiration potential. The impacts of $\mathrm{O}_{2}$ depletion and $\mathrm{CO}_{2}$ accumulation on respiration rate need to be investigated further for accurate prediction of ship hold atmospheres.

\section{Effect of storage condition on respiration rate}

The respiration rate of log sections was stable during the first two weeks after harvest. The respiration rate then decreased rapidly between weeks two through five, possibly because of depletion of soluble sugars in the harvested logs. Following this rapid decrease in respiration, low respiration rates were measured for log sections stored outdoors. However, there was an unexpected increase in respiration between twelve and twenty four weeks after harvest, particularly for log sections stored outdoors under ambient conditions (Fig. 4a). This increase may be explained by rehydration during autumn rains and consequent microbial growth. Indeed, a decline in moisture content was observed between twelve and twenty four weeks after harvest for log sections stored in outdoor uncovered conditions (Fig. 4b). Log sections stored indoors respired similarly to those stored outdoors until five weeks after harvest. Respiration of $\log$ sections stored indoors increased rapidly between five and twelve weeks after harvest compared with respiration of those stored outdoors. The respiration rate of log sections stored in humidified air increased continuously after twelve weeks, but that of log sections stored in dry air declined significantly between twelve and twenty four weeks (Fig. 4a). The increase in respiration rate of the log sections stored indoors after five weeks of storage could be attributed to the noticeable increase in mould growth (Fig. 5b). The decrease in respiration rate of log sections stored in dry air twenty four weeks after harvest was associated with moisture content declining to less than 30 \% (Fig. 4b). The lower moisture content 


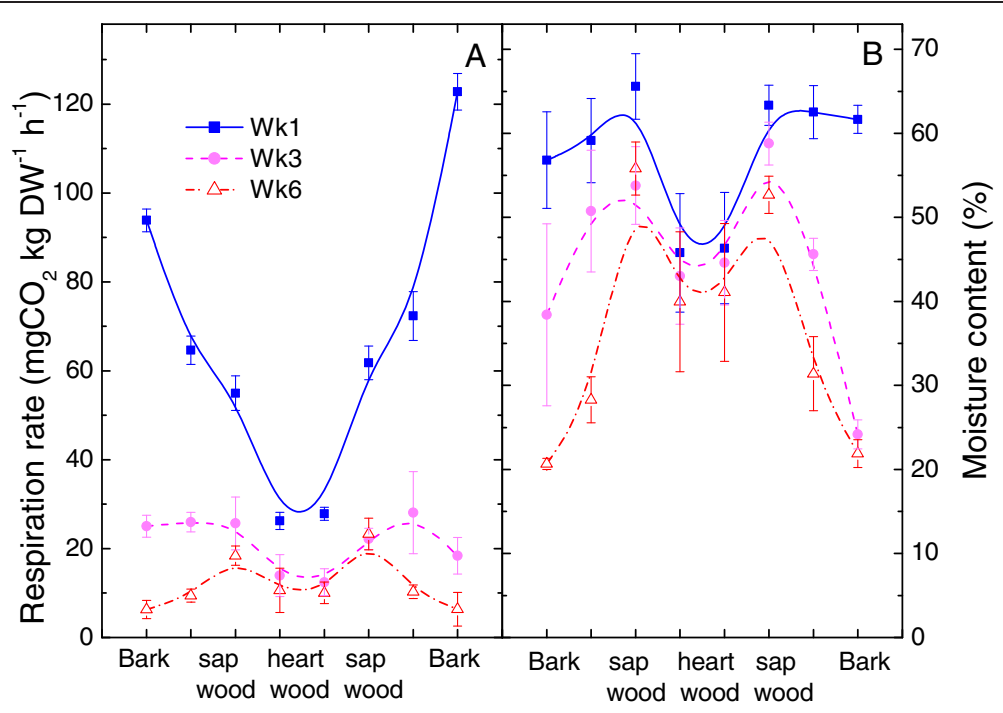

Fig. 3 Respiration rate (a) and water content (b) measured on wood tissue cut across radiata pine log sections. Each point is the means of three replicates. Vertical bars are standard errors of the means

could have limited both microbial activities and the respiration rate of the log sections. This is consistent with the lowest respiration rate recorded twelve weeks after harvest for log sections stored outdoors, when moisture content dropped to a similar range. If a drying process were introduced to reduce moisture content from $54 \%$ at harvest to about $30 \%$ prior to export, the total weight of logs would reduce to two thirds of the original. This may result in a significantly less cost for transporting logs overseas (less fuel consumption and reduced carbon footprint). However, the feasibility of such a drying process for the forest industry also depends on the cost of building and operating appropriate drying facilities. Achieving consistent moisture loss could be practically difficult due to the impact of seasonal changes in climate on the drying process (Visser et al., 2014). Without a consistent drying process, it might be necessary to adjust fumigation protocols based on assessment of moisture and microbial activity.

\section{Conclusions}

Irrespective of storage conditions, the rates of respiratory $\mathrm{CO}_{2}$ release of $\log$ sections remained high during the first two weeks post harvest and declined rapidly

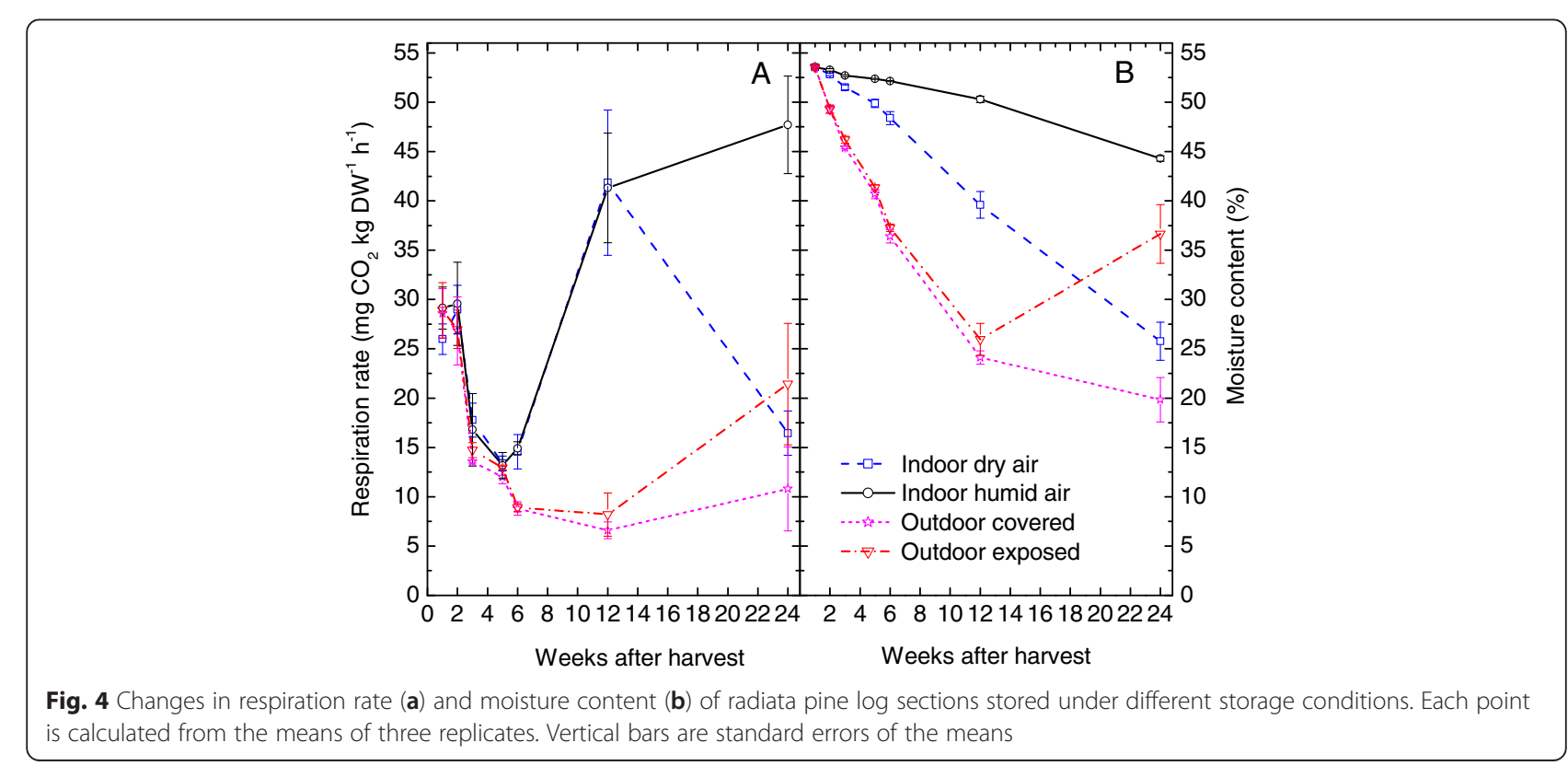




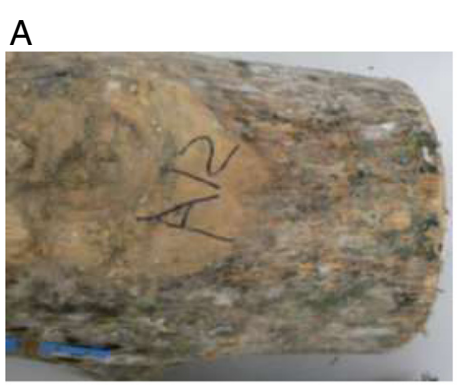

C

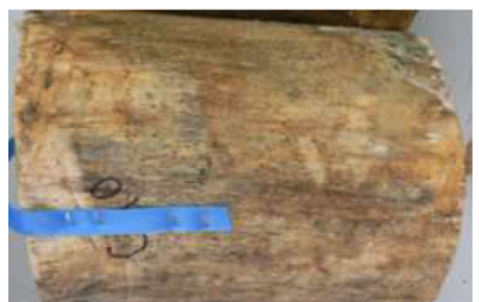

B

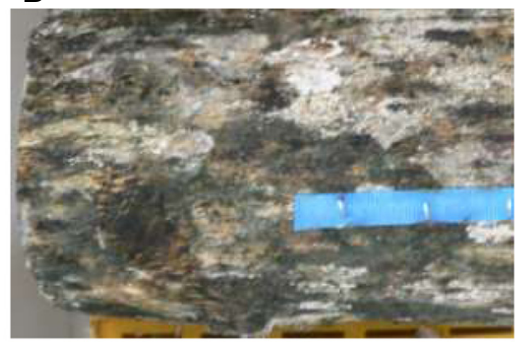

$\mathrm{D}$

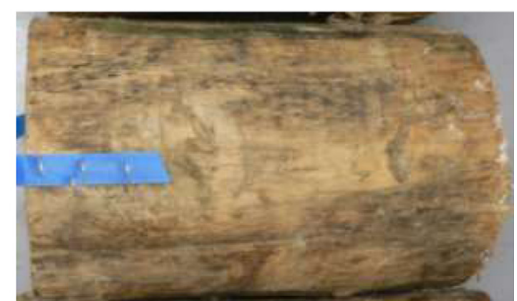

Fig. 5 Mould growth observed after 6 weeks of storage on radiata pine log sections stored indoors in dry air (a), humidified air (b), outdoors covered (c), outdoors uncovered (d)

within the next a few weeks as logs become dehydrated. A logical recommendation for the forestry industry would be to apply fumigation treatments after 4-6 weeks post harvest to reduce the interference with insecticides. The respiration rate increased nearly $50 \%$ for every $10{ }^{\circ} \mathrm{C}$ increase in temperature so the $\mathrm{CO}_{2}$ issue is exacerbated during the warm summer months when a temperature-driven stimulation of respiratory processes will result in very high $\mathrm{CO}_{2}$ concentrations in ship holds. Also, because respiratory processes are strongly dependent on moisture availability, any actions that can be taken to accelerate moisture loss will mitigate the $\mathrm{CO}_{2}$ issue.

\section{Competing interests}

The authors declare that they have no competing interests.

\section{Authors' contributions}

JF was lead author and project manager and carried out data analyses and drafted the main manuscript. AW had a supervisory role in project planning and resourcing. $X Y$ contributed to the collection of data. SO contributed to the collection of data and contributed to data analysis and the preparation of the manuscript. DB sourced the materials for trials and commented on the manuscript. AH assisted with data analyses and commented on the manuscript. BB sourced materials for trials. All authors read and approved the final manuscript.

\section{Acknowledgements}

We are very grateful to STIMBR (Stakeholders in Methyl Bromide Reduction) for funding this research project.

\section{Author details}

${ }^{1}$ The New Zealand Institute for Plant \& Food Research Limited, 120 Mt Albert Rd, Auckland 1142, New Zealand. ${ }^{2}$ The New Zealand Institute for Plant \& Food Research Limited, Batchelar Rd, Palmerston North 4474, New Zealand.

Received: 3 December 2014 Accepted: 2 June 2015

Published online: 04 July 2015

\section{References}

Brash, DW and Page, BBC. (2009). Review of phosphine research for control of timber quarantine pests. Plant \& Food Research Confidential Report No. 2370 prepared for STIMBR (Stakeholders in Methyl Bromide Reduction). Retrieved 29 May 2015 from http://maxa.maf.govt.nz/sff/about-projects/search/08-061/ phosphine-research-review.pdf

Chambers, JQ, Schimel, JP, \& Nobre, AD. (2001). Respiration from coarse wood litter in central Amazon forests. Biogeochemistry, 52, 115-131.

Damesin, C, Ceschia, E, Le Goff, N, Ottorini, J-M, \& Dufrêne, E. (2002). Stem and branchrespiration of beech: from tree measurements to estimations at the stand level. New Phytologist, 153, 159-172.

Fan, CG, \& Bi, XTT. (2013). Development of Off-Gas Emission Kinetics for Stored Wood Pellets. Annals of Occupational Hygiene, 57, 115-124.

Guidolotti, G, Rey, A, D'Andrea, E, Matteucci, G, \& De Angelis, P. (2013). Effect of environmental variables and stand structure on ecosystem respiration componentsin a Mediterranean beech forest. Tree Physiology, 33, 960-972.

Hertog, MLATM, Nicholson, SE, \& Whitmore, K. (2003). The effect of modified atmospheres on the rate of quality change in 'Hass' avocado. Postharvest Biology and Technology, 29, 41-53.

MPI (New Zealand Ministry for Primary Industries). (2013). Annual forestry export statistics. http://www.mpi.govt.nz/news-resources/statistics-forecasting/ forestry/annual-forestry-exportstatistics.aspx.

Pranamornkith, T, Hall, MKD, Adlam, AR, Somerfield, KG, Page, BBC, Hall, AJ, et al. (2014). Effect of fumigant dose, timber moisture content, end-grain sealing, and chamber load factor on sorption by sawn timber fumigated with ethanedinitrile. New Zealand Plant Protection, 67, 66-74.

Progar, RA, Schowalter, TD, Freitag, CM, \& Morrell, JJ. (2000). Respiration from coarse woody debris as affected by moisture and saprotroph functional diversity in Western Oregon. Oecologia, 124, 426-431.

Rodriguez-Calcerrada, J, Martin-StPaul, NK, Lempereur, M, Ourcival, JM, del Rey, MD, Joffre, $R$, et al. (2014). Stem $\mathrm{CO}_{2}$ efflux and its contribution to ecosystem $\mathrm{CO}_{2}$ efflux decrease with drought in a Mediterranean forest stand. Agricultural and Forest Meteorology, 195, 61-72.

Ryan, MG, Linder, S, Vose, JM, \& Hubbard, RM. (1994). Dark respiration of radiata pines (Ecological Bulletins, pp. 50-63).

Svedberg, U, Petrini, C, \& Johanson, G. (2009). Oxygen Depletion and Formation of Toxic Gases following Sea Transportation of Logs and Wood Chips. Annals of Occupational Hygiene, 53, 779-787.

Visser, R., Berkett, H., \& Spinelli, R. (2014). Determining the effect of storage conditions on the natural drying of radiata pine logs for energy use. New Zealand Journal of Forestry Science, 44:3. http://www.nzfforestryscience.com/ content/44/1/3 